\title{
Permintaan Wisata Kelompok Pemuda ke Kota Bandung
}

\section{Ayu Julida Yanti*, Yuhka Sundaya}

Prodi Ilmu Ekonomi, Fakultas Ekonomi dan Bisnis, Universitas Islam Bandung, Indonesia.

*ayujulidayanti22@gmail.com, yuhkasun@gmail.com

\begin{abstract}
This paper presents the results of research on tourist demands to the city of Bandung. The research objective is to study the demand function of tourists in the city of Bandung. Looking at the qualitative nature of tourism demand, this study examines it through the ordered logit model. Data obtained mainly from tourists visiting the city of Bandung. The estimation model repeatedly shows five factors that explain tourism demand, namely income, travel distance, leisure time owned by tourists, vehicles used to visit the city of Bandung, and the level of congestion in the city of Bandung. The biggest model coefficient is the comfort variable. Increasing leisure time one day will increase the chances of frequent categories of visits to the city of Bandung, 24,278 times greater than other categories. Klasifikasi JEL: Q21, Z23, C19
\end{abstract}

Keywords : Demand, Tourism, Ordered Logit

Abstrak. Makalah ini menyajikan hasil penelitian skripsi tentang permintaan wisatawan ke Kota Bandung. Tujuan penelitiannya adalah untuk mempelajari fungsi permintaan wisatawan di Kota Bandung. Melihat sifat kualitatif dari permintaan pariwisata, penelitian ini mengkajinya melalui model logit yang dipesan. Data diperoleh terutama dari wisatawan yang mengunjungi Kota Bandung. Model hasil estimasi berulang kali menunjukkan lima faktor yang menjelaskan permintaan pariwisata, yaitu pendapatan, jarak perjalanan wisata, waktu luang yang dimiliki oleh wisatawan, kendaraan yang digunakan untuk mengunjungi Kota Bandung, dan tingkat kemacetan di Kota Bandung. Koefisien model terbesar adalah variabel waktu luang. Menambah waktu luang suatu hari, akan memperbesar peluang kategori sering berkunjung ke Kota Bandung, 24.278 kali lebih besar dari kategori lainnya. Klasifikasi JEL : Q21, Z23, C19

Kata Kunci: Permintaan, Pariwisata, Ordered Logit 


\section{A. Pendahuluan}

Wisata adalah kegiatan individu atau rumah tangga yang menggunakan waktu senggangnya untuk memperoleh manfaat dari kunjungan ke tempat-tempat yang memiliki beragam nilai. Mulai dari nilai keindahan, edukasi, hingga spiritual. Pada masyarakat perkotaan, curahan waktu untuk wisata tampak telah menjadi agenda rumah tangga, ditengah kesibukan ragam pekerjaanya.

Jawa Barat memiliki banyak ragam wisata yang tersebar disetiap daerahnya. Tiga terbesar diantaranya adalah Kabupaten Cirebon, Kabupaten Garut dan Kota Bandung. Kabupaten Cirebon memiliki 80 obyek wisata, Kabupaten Garut 59 obyek wisata, dan Kota Bandung 51 obyek wisata. Kabupaten Cirebon dan Garut, obyek wisatanya berbasis alam. Sementara Kota Bandung, dengan ciri perkotaan, adalah satu-satunya kota yang memiliki paling banyak obyek wisata (Dinas Pariwisata dan Kebudayaan Provinsi Jawa Barat, 2018).

Kota Bandung merupakan Ibu Kota Jawa Barat sekaligus Metropolitan terbesar di Provinsi Jawa Barat. Kota Bandung adalah kota sejarah. Sejarah kemerdekaan negara Asia Afrika dideklarasikan di Kota Bandung. Kota Bandung memiliki akses yang memudahkan bagi wisatawan luar. Wisatawan dapat menggunakan jalur darat dan jalur udara. Kota Bandung memiliki Bandara Internasional Husein Sastranegara. Memiliki beberapa stasiun kereta api, dan pintu tol dari arah barat, timur, utara dan selatan.

Kota Bandung memiliki gejala penurunan kunjungan wisatawan. Seperti yang ditampilkan pada Gambar 1, mencermati jumlah wisatawan di Kota Bandung periode 20112016, terdapat indikasi penurunan pada tahun 2016. Gejalanya dilihat penurunan wisatawan macanegara dan domestik. Bahkan, setelah Bandara Internasional Jawa Barat (BIJB) Kertajati dioperasikan, terdapat tekanan agar Bandara Husein Sastranegara ditutup. Padahal jumlah wisatawan mancanegara ke Kota Bandung lebih besar dari wisatawan domestik.

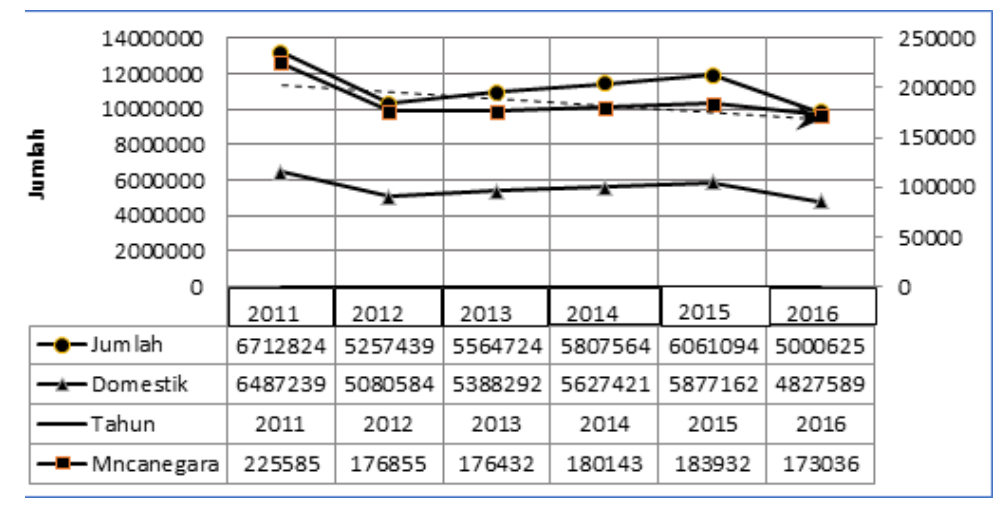

Sumber : Badan Pusat Statistik Kota Bandung, 2019

Gambar 1. Jumlah kunjungan wisatawan Mancanegara dan Domestik ke Kota Bandung 20112016

Wisatawan adalah rumah tangga yang memiliki beragam pertimbangan untuk melakukan wisata. Sebagai rumah tangga, keputusan mereka untuk berwisata ke Kota Bandung bersumber dari pertimbangan yang beragam. Pertimbangannya mungkin berdasar pada daya tarik Kota Bandung, kemampuan daya belinya, waktu yang tersedia, akses ke Kota Bandung, tingkat kemacetan, dan mungkin banyak pertimbangan lain.

Curahan waktu untuk berwisata ke Kota Bandung menampilkan sifat kualitas. Suatu rumah tangga bisa melakukan pengulangan kunjungan ke Kota Bandung. Pengulangan tersebut tidak diketahui dengan pasti apakah sangat sering, sering, atau kurang. Dari sudut pandang ilmu 
ekonom, kunjungan wisatawan dapat dikaji dari sudut pandang permintaan pasar, yaitu permintaan wisatawan ke Kota Bandung. Informasi empiris mengenai sifat permintaannya perlu dipahami, sedemikian hingga diperoleh keterangan mengenai kepekaan faktor penyebabnya. Sebagaimana ditampilkan pada Gambar 1, sekurang-kurangnya terdapat dua kelompok populasi yang perlu dipahami, yaitu populasi wisatawan mancanegara dan domestik. Dua populasi itu juga menampilkan keragaman demografis di dalamnya.

\section{B. Landasan Teori}

Permintaan wisata dapat dipahami dari pilihan rumah tangga. Sinclair (2002), membangun logikanya dari asumsi yang sangat sederhana. Rumah tangga dianggap menghadapi dua pilihan, yaitu konsumsi waktu senggang, T, dengan konsumsi beragam barang, G. Utility, U, dari kedua jenis konsumsi tersebut diekpresikan pada persamaan (1). Persamaan (1) disebut fungsi primitif, dan secara eksplisit, fungsi utility tersebut dianggap memiliki sifat derajat 1 , sebagaimana disajikan pada persamaan $\left(1^{*}\right)$. Fungi tersebut diasumsikan cembung, sehingga menangkap sifat jenuh jika konsumsi $\mathrm{T}$ dan $\mathrm{G}$ terus bertambah. Dalam literatur ekonomi disebut dengan marginal utility yang menurun. Trade-off utility $\mathrm{T}$ dan $\mathrm{G}$, dalam literature mikroekonomi, diilustrasikan dengan kurva seperti hurup U miring ke kanan. Istilah formalnya adalah indifference curve.

$\mathrm{U}(\mathrm{T}, \mathrm{G})$

$\mathrm{U}=\mathrm{T} . \mathrm{G}$

Anggaran, M, untuk memenuhi kebutuhan T dan G disajikan pada persamaan (2). Notasi PT dan PG, secara berurutan menampilkan harga dari T dan G. Harga T masih bersifat abstrak, karena konkritnya menampilkan definisi yang rumit, tidak seperti harga barang yang satuannya mudah dipahami.

$\mathrm{M}=\mathrm{PT} \cdot \mathrm{T}+\mathrm{PG} \cdot \mathrm{G}$

Persamaan (1) dan (2), jika diekspresikan dalam bentuk grafis pada Gambar 2, maka menampilkan apa yang disebut dengan teori keseimbangan konsumen. Jika diasumsikan bahwa rumah tangga menghabiskan anggarannya untuk $\mathrm{T}$ atau $\mathrm{G}=0$, maka $\mathrm{T}=\mathrm{M} / \mathrm{PT}$. Sebaliknya, jika anggarannya dihabiskan untuk konsumsi $\mathrm{G}$ atau $\mathrm{T}=0$, maka $\mathrm{G}=\mathrm{M} / \mathrm{PG}$. Dua keputusan ekstrim menampilkan apa yang disebut dengan garis anggaran atau budget line.

Pada tingkat M, PT dan PG tertentu, konsumen akan memperoleh manfaat dari konsumsi T sebesar $0 T^{*}$, dan konsumsi G sebanyak $0 \mathrm{G}^{*}$. Pilihan optimal ketika budget line bersinggungan dengan indifference curve pada satu titik. Konkritnya, pilihan optimal ditetapkan dengan mempertimbangkan kemampuan anggaran dan manfaat yang akan diperoleh dari beragam jenis barang.

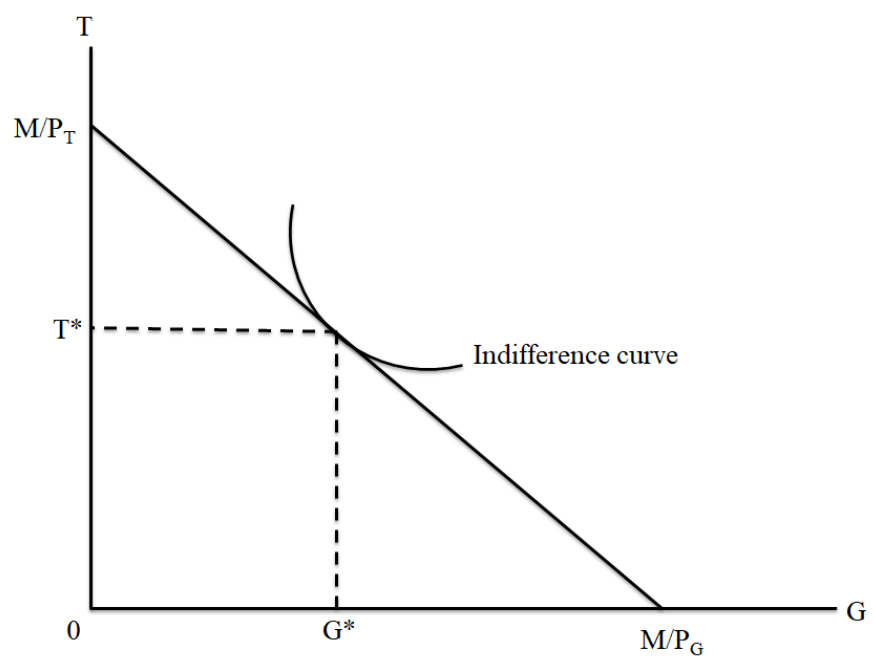

Gambar 2. Keseimbangan Konsumen

Hipotesis mengenai permintaan wisata dapat diturunkan dari fungsi permintaan wisata. 
Sebelum ke arah sana, logika ekspresi permintaan perlu diuraikan terlebih dahulu. Tujuan rumah tangga untuk memperoleh atau memaksimumkan utility dengan mempertimbangkan kendala anggaran, diekspresikan oleh persamaan Lagrange pada persamaan (3). Agar memperoleh solusi matematis yang eksplisit, digunakan fungsi utility yang eksplisit (persamaan $\left(1^{*}\right)$ ).

$\mathrm{L}=\mathrm{T} . \mathrm{G}+\lambda\left(\mathrm{M}-\mathrm{P}_{\mathrm{T}} . \mathrm{T}+\mathrm{P}_{\mathrm{G}} \cdot \mathrm{G}\right)$.

Turunan pertama persamaan (3), secara berurutan terhadap variabel keputusan : T, G dan $\lambda$, disajikan pada persamaan (4). Turunan tersebut simbol dari perubahan manfaat bersih $(\partial \mathrm{L})$ akibat perubahan konsumsi waktu senggang $(\partial \mathrm{T})$, barang konsumsi $(\partial \mathrm{G})$ dan anggaran $(\partial \lambda)$.

$\partial \mathrm{L} / \partial \mathrm{T}=\mathrm{G}-\lambda \mathrm{P}_{\mathrm{T}}=0$ atau $\mathrm{G}=\lambda \mathrm{P}_{\mathrm{T}}$

$\partial \mathrm{L} / \partial \mathrm{G}=\mathrm{T}-\lambda \mathrm{P}_{\mathrm{G}}=0$ atau $\mathrm{T}=\lambda \mathrm{P}_{\mathrm{G}}$

$\partial \mathrm{L} / \partial \lambda=\mathrm{M}-\mathrm{P}_{\mathrm{T}} . \mathrm{T}+\mathrm{P}_{\mathrm{G}} \cdot \mathrm{G}$

Solusi dari sistem persamaan (4) menghasilkan fungsi permintaan $\mathrm{T}$ dan $\mathrm{G}$ yang ditampilkan pada persamaan (5).

$\mathrm{T}^{*}=\mathrm{M} / \mathrm{P}_{\mathrm{T}}$

$\mathrm{G}^{*}=\mathrm{M} / \mathrm{P}_{\mathrm{G}}$

Secara aggregat, permintaan $T$ dan $G$ merespons perubahan anggaran, $M$, dan harga $T$ dan $G$. Teori merekomendasikan bahwa untuk mengkaji permintaan wisata, T*, sekurangkurangnya perlu mempelajari variabel $\mathrm{M}$ dan harga-harga. Hipotesis umum dari persamaan itu, pertama, jika $\mathrm{P}_{\mathrm{T}}$ meningkat, dengan asumsi $\mathrm{M}$ konstan, maka permintaan terhadap waktu senggang untuk wisata, $\mathrm{T}^{*}$, akan menurun. Kedua, jika anggaran rumah tangga naik, dengan asumsi $\mathrm{P}_{\mathrm{T}}$ konstan, maka permintaan wanggu senggang untuk wisata, $\mathrm{T}^{*}$, akan meningkat. Efek dari perubahan harga barang lain, $\mathrm{P}_{\mathrm{G}}$, terhadap $\mathrm{T}^{*}$, bisa beragam, tergantung dari hubungan $\mathrm{T}$ dan $\mathrm{G}$, apakah subsitusi atau komplementer.

Hipotesis yang bersifat khusus, konteks wisata, perlu membedah apa itu $\mathrm{P}_{\mathrm{T}}$. Apabila diartikan sebagai harga wisata, maka akan bermakna sangat abstrak. $\mathrm{P}_{\mathrm{T}}$ menampilkan beban uang yang harus dibayar oleh wisatawan. Beban itu dapat berupa biaya transportasi, yang di dalamnya melekat jarak tempuh, dan tingkat kemacetan di daerah tujuan wisata. Melalui pemahaman teoritis, hasil ulasan literatur, dan logikanya, hasil penelitian ini, menampilkan fungsi permintaan wisata dari luar Kota Bandung, $i$, ke Kota Bandung, $j$, sebagaimana disajikan pada persamaan (6).

$\mathrm{T}_{\mathrm{ij}}=\mathrm{f}($ Anggaran, Jarak Tempuh, Ketersediaan Waktu Luang, Kendaraan, Kemacetan $)$

Munculnya variabel anggaran pada persamaan (6) berasal dari persamaan (5). Variabel anggaran, secara operasional, dapat diproksi dari besarnya pengeluaran wisatawan. Sementara itu, variabel penjelas lain diperoleh dari pengalaman peneliti lain.

Meningkatnya anggaran wisatawan berarti meningkatnya kemampuan atau daya beli. Dengan demikian muncul hipotesis pertama, meningkatnya anggaran wisatawan, maka dapat mendorong mereka untuk meningkatkan kunjungan ke Kota Bandung.

Jarak tempuh wisatwan ke Kota Bandung menjadi salah satu kendala. Semakin jauh jarak wisatawan ke Kota Bandung, maka curahan waktu dan biaya juga akan semakin besar. Hipotesis kedua menyatakan bahwa semakin jauh jarak wisatawan ke Kota Bandung, maka dorongannya untuk wisata akan berkurang.

Kegiatan wisata hanya mungkin dilakukan ketika libur. Hari libur adalah waktu luang yang tersedia bagi wisatawan. Hipotesis ketiga menyatakan bahwa semakin jauh jarak tempuh wisatawah ke Kota Badung, maka akan mengurangi kunjungan ke Kota Bandung.

Jenis kendaraan yang digunakan wisatawan merupakan bagian dari kemampuan wisatawan. Akses ke Kota Bandung dapat menggunakan transportasi udara, kereta, dan jalan tol. Hipotesis keempat menyatakan bahwa semakin wisatawan mampu menggunakan transportasi yang cepat dan bebas hambatan, maka dorongan wisata ke Kota Bandung akan meningkat.

Kota Bandung, sempat dijuluki kota termacet. Kemacetan diperkirakan akan mengurangi minat wisatawan. Waktu senggangny akan habis dalam perjalanan. Oleh karena itu, hipotesis kelima menyatakan bahwa, semakin tinggi tingkat kemacetan di Kota Bandung, maka 
akan mengurangi minat wisatawan ke Kota Bandung.

\section{Hasil Penelitian dan Pembahasan}

Permintaan wisata ke Kota Bandung, dalam penelitian skripsi ini, secara metode, diperlakukan sebagai sifat ordinal. Peneliti membangun anggapan bahwa kunjungan wisatawan ke Kota Bandung dapat dilakukan secara berulang oleh wisatawan. Oleh karena itu, ekspresi permintaannya menampilkan 4 kategori : Sangat Sering, Sering, Jarang, dan Tidak Pernah. Kategori keempat tetap diungkapkan untuk menampilkan ekspresi pengulangan kunjungan wisatawan. Notasi "T", pada landasan teori, dioperasionalisasikan dengan frekuensi kunjungan wisata ke Kota Bandung.

Metode regresi biasa tidak dapat digunakan untuk memenuhi sifat ordinal. Variasi antar variabel dependennya tidak akan menghasilkan koefisien. Green (2002) serta Park (2009), yang menjadi refferensi Sundaya (2011), menggunakan model ordered logit untuk mengestimasi variabel independen yang bersifat kualitafif atau ordered. Penelitian ini mengadopsi teknik tersebut, dan menghasilkan cara membaca koefisien yang berbeda, karena diestimasi dengan teknik maximum likelihood.

Sample yang digunakan untuk merepresentasikan karakteristik wisatawan cukup rumit. Sebagaimana disajikan pada pendahuluan, ada dua kelompok besar, yaitu wisatawan mancanegara, dan wisatawan domestic. Wisatawan domestik juga sulit untuk menangkap sifat umumnya, karena data populasinya tidak tersedia, bahkan dianggap tak terbatas, karena wisatwan domestik juga bisa dari beragam daerah dengan latar belakang yang berbeda-beda. Oleh karena itu, timbul kesulitan dalam menentukan jumlah sampel.

Sample penelitan ini terbatas untuk menjelaskan karakteristik wisatawan generasi muda. Respondennya berumur di bawah 35 tahun, dan motivasinya adalah liburan atau berwisata ke Kota Bandung. Oleh karena itu, permintaan wisata dalam penelitian ini hanya menggambarkan kelompok generasi muda dengan umur tersebut.

Data yang digunakan untuk mengestimasi model ekonometrika ordered logit adalah data primer. Data primer digali dengan menggunakan wawancara yang dibantu dengan kuesioner. Pertanyaannya mencakup variabel yang diidentifikasi pada landasan teori, yaitu : frekwensi kunjungan ke Kota Bandung, anggaran yang dikeluarkan, jarak tempuh, ketersediaan waktu luang, kendaraan, dan kemacetan di Kota Bandung. Pertanyaan itu hasil sortir dari banyak pertanyaan lain, yang, dalam upaya menggali beragam faktor yang menjadi arti penting bagi wisatawan untuk memutuskan berwisata ke Kota Bandung.

Hasil estimasi pendugaan model ekonometrika ordered logit ditampilkan pada Tabel 1. Hasil tersebut diperoleh setelah melakukan respesifikasi model secara berulang untuk memenuhi kriteria logika, ekonomi dan statistik. Awalnya telah diduga banyak faktor yang mencerminkan faktor ekonomi dan non ekonomi, dan hasil akhirnya terdapat lima variabel yang penulis pilih untuk peluang frekuensi wisatawan berwisata ke Kota Bandung dengan kategori sangat sering, sering, jarang, dan tidak pernah. faktor ekonominya adalah pendapatan (EXP) dan faktor non ekonominya adalah jarak tempuh (JT), waktu luang (WL), kendaraan yang digunakan (KNDRAN), dan kemacetan (KMCTN).

Tabel 1. Hasil pendugaan model ekonometrika ordered logit 


\begin{tabular}{lrrrrr}
\hline Variabel & Koefesien & Standar error & $Z$ stat & $\mathrm{P}>|z|$ & Mean of X \\
\hline EXP & 0.0348 & 0.0180 & 1.928 & 0.0539 & 11.3240 \\
JT & 0.2897 & 0.1972 & 1.469 & 0.1418 & 2.8397 \\
WL & 3.1896 & 2.3573 & 1.353 & 0.1760 & 0.2370 \\
KNDRAN & -0.2724 & 0.1634 & -1.667 & 0.0956 & 2.130 \\
KMCTN & -0.3994 & 0.1701 & -2.347 & 0.0189 & 3.963 \\
\hline$\mu_{1}$ & 1.9441 & 0.2327 & 8.262 & 0.0000 & \\
$\mu_{2}$ & 3.6984 & 0.2736 & 13.450 & 0.0000 & \\
\hline Log likelihood Function; R Square; McFadden's $=-115.0440$ & \\
Chi squared & & $=22.48982$ & \\
Prob[ChiSqd > value] & & & $=0.4224$
\end{tabular}

Sumber: Hasil Pendugaan Model dengan LIMDEP.

Nilai statistic $\mathrm{P}>|\mathrm{z}|$ pada kolom 5 Tabel 2 menampilkan peluang signifikansi setiap variabel penjelas terhadap permintaan wisata. Secara keseluruhan, nilai statistiknya di bawah 0.2 , artinya setiap variabel penjelas signifikan mempengaruhi permintaan wisata dengan peluang kesalahan di bawah 20 persen.

Hasil pendugaan menampilkan z statistik variabel pendapatan (EXP) sebesar 1.928 dengan p-value sebesar 0.0539. Nilai p-value memberikan informasi bahwa koefesien pendapatan wisatawan (EXP) berbeda nyata dengan nol pada kecenderungan tingkat kesalahan pendugaan sebesar 0.0539 , lebih rendah dari 0.05 . Simpulan serupa ditunjukkan juga oleh nilai uji statistik z jarak tempuh (JT) dan waktu luang (WL) sebesar 1.469 dan 1.353 dengan p-value 0.1418 dan 0.1760 . Nilai p-value memberikan simpulan bahwa variabel JT dan WL berbeda nyata dengan nol pada kecenderungan tingkat kesalahan pendugaan 0.1418 dan 0.1760 lebih rendah dari 0.05. Sementara itu, koefesien variabel kendaraan yang digunakan saat mengunjungi Kota Bandung (KNDRAN), dan kemacetan yang dilalui wisatawan (KMCTN) menampilkan uji statistik z sebesar -1.667 dan -2.347 berbeda nyata dengan nol pada kecenderungan tingkat kesalahan sebesar 0.0965 dan 0.0189 lebih rendah dari 0.05 .

Koefisien model ordered logit berbeda dengan cara membaca koefisien dari hasil regresi biasa, yang menggunakan minimisasi error. Keofisien modelnya dibaca melalui apa yang disebut dengan odds ratio. Tabel 3 menampilkan odds ratio yang dikembangkan dari koefesien pada Tabel 2. Odds ratio pada tabel tersebut menjelaskan peluang frekuensi wisatawan berwisata ke Kota Bandung dengan kategori sangat sering, sering, jarang, dan tidak pernah dalam merespon perubahan pada nilai tertentu pada masing-masing variabel penjelas. Pada tabel tersebut terdapat dua kolom odds ratio yang diinterpretasikan, yaitu kolom [2] dan [4]. Perbedaannya, besaran pada kolom [2] menampilkan informasi menganai berapa besar peluang sangat sering dibandingkan sering, jarang dan tidak pernah secara tetap bergantian dalam merespon perubahan pada satu satuan besaran setiap variabel penjelas, dengan asumsi tidak terdapat perubahan pada variabel penjelas lainnya. Besaran kolom [4] memiliki pengertian serupa dengan bentuk penjelasan kolom [2], perbedaannya terletak pada satuan besar variabel penjelas. Satuan yang digunakan pada kolom [4] adalah standar deviasi yang disajikan pada kolom [3].

Tabel 2. Odds Ratio model ekonometrika ordered logit

\begin{tabular}{lrrr}
\hline Variabel & $\mathrm{e}^{\wedge} \mathrm{b}$ & $\mathrm{Stdv}$ & $\mathrm{e}^{\wedge} \mathrm{b} \operatorname{StdX}$ \\
{$[1]$} & {$[2]$} & {$[3]$} & {$[4]$} \\
\hline EXP & 1.0354 & 17.0932 & 4855 \\
JT & 1.3360 & 2.0422 & 15.3080 \\
WL & 24.278 & 0.8245 & 4935
\end{tabular}




$\begin{array}{lrrr}\text { KNDRAN } & 0.761 & 1.17796 & 2.4508 \\ \text { KMCTN } & 0.6707 & 2.4377 & 5.1292\end{array}$

Sumber: Hasil Pendugaan Model dengan LIMDEP.

Hasil Odds ratio menjelaskan permintaan wisata ke Kota Bandung. Hasil odds ratio variabel pendapatan sebesar 1.0354. Hasil odds ratio variabel jarak tempuh sebesar 1.3360. Hasil odds ratio variabel waktu luang sebesar 24.278. Hasil odds ratio variabel kendaraan yang digunakan mengunjungi Kota Bandung sebesar 0.761 dan hasil odds ratio variabel kemacetan sebesar 0.6707 .

Hasil pendugaan pada kolom [2], memunculkan infomasi bahwa kenaikan pendapatan (EXP) sebesar 100 ribu rupiah berpotensi untuk menciptakan peluang sangat sering $1.0354 \mathrm{kali}$ lebih tinggi dibandingkan peluang sering, peluang jarang dan peluang tidak pernah. Efek pendapatan wisatawan berpengaruh signifikan terhadap jarak tempuh dimana variabel penjelas ini mempengaruhi peluang sangat sering, sering, jarang dan tidak pernah. Pada kolom [2] ditunjukkan bahwa ketika jarak tempuh yang dilalui wisatawan berkurang 1 jam pada saat berwisata ke Kota Bandung, peluang untuk sangat sering adalah 1.3360 kali lebih tinggi dibandingkan peluang sering, jarang dan tidak pernah. Jarak tempuh menjadi salah satu keputusan wisatawan untuk berwisata.

Begitupun halnya, waktu luang merupakan salah satu faktor yang mempengaruhi frekuensi berkunjung, yang dimaksud dengan frekuensi berkunjung disini adalah frekuensi yang menunjukkan seberapa sering pengunjung datang ke Kota Bandung untuk berwisata dan lamanya waktu yang dihabiskan untuk mengunjungi kota Bandung. Seperti yang ditunjukkan pada tabel 7 kolom [2], apabila bertambahnya waktu luang sebesar 1 hari, maka peluang sangat sering wisatawan berwisata akan 24.278 kali lebih tinggi dibandingkan peluang sering, jarang, dan tidak pernah.

Adapun variabel penjelas lainnya adalah kendaraan yang digunkan pada saat berwista ke Kota Bandung. Karena kendaraan yang digunakan menentukan waktu, tenaga dan biaya yang dikeluarkan ini pula menjadi salah satu faktor wisatawan berwisata dengan menggunakan berbagai transportasi misalnya: pesawat, kereta api, mobil dan motor. Pada kolom [2] tabel 7. Variabel ini memberikan isyarat mengenai kapasitas wisatawan yang dilihat dari kepemilikan kendaraan. Apabila wisatawan tidak memiliki kendaraan pribadi, maka peluang sangat sering ke Kota Bandung sebesar 0.761 lebih tinggi dibandingkan peluang sering, jarang, dan tidak pernah. Sebaliknya, jika mereka memiliki kendaraan pribadi, maka peluang untuk sering ke Kota Bandung akan lebih besar.

Variabel penjelas terakhir yaitu kemacetan (KMCTN) dimana kemacetan dimana kemacetan hal yang paling dihindari oleh wisatawan karena akan memakan banyak waktu dan tenaga. Dilihat pada kolom [2] tabel 7. Ditunjukan kemacetan mempengaruhi wisatawan sebesar 1 jam, maka peluang sangat sering sebesar 0.6707 lebih tinggi dibandingkan peluang sering, jarang, dan tidak pernah.

Monaco (2018) memandang bahwa permintaan wisata pada generasi muda milenial menampilkan sifat khusus. Sumber daya informasi melalui internet, menurutnya, menjadi pemicu generasi muda untuk merencanakan wisata. Teknologi informasi inilah yang memberikan visualisasi dan akhirnya mendorong generasi muda, dengan beragam cara, misal bagpacker style, untuk memperoleh manfaat dari wisata ke beragam tempat tujuan.

Analisis ekonomi terhadap wisata, berdasarkan studi literatur, cukup banyak yang concern terhadap kajian sifat permintaanya. Informasi sifat permintaan memiliki manfaat praktis, yaitu dapat mengidentifikasi kebijakan ekonomi dalam rangka meningkatkan kunjungan wisatawan.

Tahun 2016, Agustina (2016), melakukan penelitian tentang faktor-faktor yang 
mempengaruhi permintaan jasa wisata di Kota Bandung. Ia menjelaskan jasa pariwisata yang dideterminasi oleh harga, pendapatan konsumen dan daya tarik wisata. Variabel pendapatan konsumen, dalam penelitian skripsi ini, adalah sepadan dengan anggaran wisatawan yang diproksi dengan pengeluarannya, karena sangatlah sulit untuk secara obyektif menggali data pendapatan yang sifatnya cukup rahasia bagi individu responden. Jasa pariwisata, dalam konteks penelitian ini adalah fasilitas wisatwan potensial untuk akses ke Kota Bandung.

Penelitian Nurlaela (2018), dapat menginspirasi penelitian lanjutan. Ia menganalisis sifat permintaan wisata melalui pilihan multinomial. Pilihan multinomial masih satu rumun dengan ordered logit dalam konteks qualitative dependent variables (QDV). Pilihan multinomial memberikan informasi mengenai peluang wisatawan untuk memilih beberapa obyek wisata. Kota Bandung beragam obyek wisatanya. Variasi harga atau tariff beberapa obyek wisata memungkinkan sekali untuk dimunculkan informasi kuantitatifnya melalui multinomial logit.

\section{Kesimpulan}

Kesimpulan dari penelitian skripsi ini disajikan sebagai berikut :

1. Permintaan wisatawan ke Kota Bandung dijelaskan oleh pendapatan, jarak tempuh, waktu luang, kendaraan yang digunakan mengunjungi Kota Bandung dan kemacetan

2. Kenaikan pendapatan sebesar 100 ribu rupiah berpotensi untuk menciptakan peluang sangat sering 1.0354 kali lebih tinggi dibandingkan peluang sering, peluang jarang dan peluang tidak pernah.

3. Ketika jarak tempuh yang dilalui wisatawan berkurang 1 jam pada saat berwisata ke Kota Bandung, peluang untuk sangat sering adalah 1.3360 kali lebih tinggi dibandingkan peluang sering, jarang dan tidak pernah.

4. Bertambahnya waktu luang sebesar 1 hari, maka peluang sangat sering wisatawan berwisata akan 24.278 kali lebih tinggi dibandingkan peluang sering, jarang, dan tidak pernah.

5. Wisatawan yang memiliki kendaraan pribadi memiliki peluang besar untuk sangat sering berwisata ke Kota Bandung.

6. Kemacetan sebesar 1 jam, maka peluang sangat sering sebesar 0.6707 lebih tinggi dibandingkan peluang sering, jarang, dan tidak pernah.

\section{E. Saran}

Penelitian skripsi ini telah menampilkan bagaimana sifat permintaan wisata ke Kota Bandung. Pemerintah Kota Bandung dapat meningkatkan daya saing wisata dengan cara memecahkan masalah kemacetan. Masalah ini adalah masalah yang dinamis, karena terdapat kekuatan eksternal yang senantiasa menjadi tekanan ke Kota Bandung. Gagasan yang berpotensi untuk mengeliminasi masalah kemacetan adalah dengan membangun shelter di setiap atau beberapa pintu masuk strategis ke Kota Bandung. Kemungkinan, ada wisatawan yang ingin praktis dengan memanfaatkan moda transportasi lokal khusus wisawatan luar. Ini juga dapat menjadi bagian dari badan usaha milik Pemerintah Kota Bandung yang dapat memberikan kontribusi bagi penerimaan daerah.

Mencermati ulasan literatur, tampaknya, diperlukan penelitian lanjutan. Penelitian lanjutan yang disarankan adalah meneliti aspek permintaan ke Kota Bandung dengan pendekatan multinomial choice, sehingga dapat menghasilkan informasi, obyek-obyek wisata yang berpeluang besar untuk dikunjungi oleh wisatawan, dengan harga atau tariff yang bervariasi.

Penelitian skripsi ini terbatas menjelaskan sifat permintaan wisata pada generasi muda. Masih banyak kelompok wisatawan lainya. Oleh karena itu, peneliti yang memiliki agenda akademik untuk menambah informasi analisis permintaan wisata ke Kota Bandung, dapat mencoba untuk mengambil kelompok wisatawan lain, misalnya wisatawan mancanegara yang jumlahnya lebih banyak ke Kota Bandung. 


\section{Daftar Pustaka}

[1]Badan Pusat Statistik. (2018, April 20). Retrieved from Https://Bandungkota.Bps.Go.Id/Statictable/2017/08/29/120/Jumlah-WisatawanMancanegara-Dan-Domestik-Di-Kota-Bandung-2016.Html

[2] Dinas Kebudayaan dan Pariwisata. (2018). Retrieved from Dinas Kebudayaan dan Pariwisata - Organizations - Portal Data Kota Bandung.

[3] Agustina, S. (2016). Analisis Faktor- Faktor yang Mempengaruhi Permintaan Jasa Wisata di Kota Bandung. Tesis. Universitas Pendidikan Indonesia.

[4] Gray, H. P. (1966). The Demand for International Travel by the United States and Canada . Wiley for the Economics Department of the University of Pennsylvania and Institute of Social and Economic Research, Osaka University.

[5] Green, W. H. (2002). Econometric Analysis. Prentice-Hall, New Jersey: Fifth Edition.

[6] Monaco, S. (2017). Tourism and the new generations: emerging trends and social implications in Italy. Salvatore Monaco is based at the Department of Social Sciences, University of Naples Federico II, Naples, Italy.

[7] Nurlela, S, N. (2018). An application of Multinomial Logit Model (MNL) on tourist destination choices. Urband and Regional Planing Departement, Faculty of Architecture Design and Planing, Institut Teknologi Sepulung November.

[8] Park, H. M. (2009). Regression Models for Ordinal and Nominal Dependent Variables Using SAS, Stata, LIMDEP, and SPSS. The University Information Technology Services (UITS) Center for Statistical and Mathematical Computing, Indiana University.

[9] Sinclair, M. T., \& Stabler, M. (2002). The Economics of Tourism. London and New York. 